$$
\begin{array}{r}
\text { AGRICULT } \\
\text { DE PEQUENA ES } \\
\text { E SUAS IMPLICAÇÕ } \\
\text { TRANSIÇÃO AGROECOLÓGIC } \\
\text { AMAZÔNIA BRASI }
\end{array}
$$




\section{AGRICULTURA DE PEQUENA ESCALA E SUAS IMPLICAÇÕES NA TRANSIÇÃO AGROECOLÓGICA NA AMAZÔNIA BRASILEIRA}

\section{U C I A N O M A T T O S}

EMPRESA BRASILEIRA DE PESQUiSA AgropeCUÁRIA, EMBRAPA, BRASIL

E D U A R D O B R O N D I Z I O

INDIANA UNIVERSITY, IU, USA

A D E M A R R O M E I RO

UNIVERSIDADE ESTADUAL DE CAMPINAS, UNICAMP, BRASIL

$$
\text { R O D R I G O O RA I R }
$$




\section{Resumo}

\section{AGRICULTURA DE PEQUENA ESCALA E SUAS IMPLICAÇÕES NA TRANSIÇÃO AGROECOLÓGICA DA AMAZÔNIA BRASILEIRA}

Os dados do Censo Agropecuário 2006 apresentam um retrato da agricultura brasileira de pequena escala e realçam a sua importância na produção de alimentos e na geração de empregos no campo. Dentro do contexto revelado no Censo, o presente artigo discute a implicação de diferentes termos, como agricultura tradicional e agricultura familiar, usados na definição de agricultura de pequena escala no Brasil. Como estudo de caso, o artigo utilizou dados de 2.400 lotes rurais familiares, localizados em sete projetos de colonização e selecionados pela política pública piloto Proambiente, para discutir a influência de variáveis (sócio-demográficas, econômicas e de infra-estrutura) no uso da terra na Amazônia brasileira. $\mathrm{O}$ artigo conclui que o acesso à infraestrutura e ao crédito rural são importantes na promoção de diferentes trajetórias de transição agroecológica entre produtores de pequena escala da Amazônia brasileira.

Palavras-chaves: uso da terra, economia ecológica, economia agrícola, agricultura tradicional, agricultura familiar, transição agroecológica, Amazônia.

\section{Abstract \\ SMALL SCALE AGRICULTURE AND ITS IMPLICATIONS IN THE BRAZILIAN AMAZON AGROECOLOGICAL TRANSITION}

The National Agricultural Census of 2006 presented, for the first time, a portrait of small scale agriculture in Brazil, highlighting its central importance in terms of food production and rural employment. Using the 2006 census as a context, this article discusses the implications of different terms, such as traditional agriculture and family agriculture, used to define small scale agriculture in Brazil. We use data from 2,400 families in seven colonization settlements included as part of the Brazilian pilot public policy program Proambiente to discuss the influence of variables (e.g. socio-demographic, economic, and infrastructure) on the land use in the Brazilian Amazon. The article concludes by stressing the importance of infrastructure and rural credit in promoting different trajectories 
of agroecological transitions among small scale producers in the Brazilian Amazon.

Keywords: land use, ecological economics, agricultural economics, traditional agriculture, family agriculture, agroecological transition, Amazon Basin.

\section{Resumen}

\section{AGRICULTURA DE PEQUEÑA ESCALA Y SUS CONSECUENCIAS EN LA TRANSICIÓN AGROECOLÓGICA DE LA AMAZONÍA BRASILEÑA}

El Censo Nacional Agropecuario de 2006 presentó, por primera vez, un retrato de la agricultura en pequeña escala en Brasil, destacando su importancia central en términos de producción alimentaria y el empleo rural. Utilizando el censo de 2006 como un contexto, este artículo analiza las implicaciones de los diferentes términos, como la agricultura tradicional y la agricultura familiar, que sirven para definir la agricultura a pequeña escala en Brasil. Hemos utilizado los datos de 2.400 familias en siete asentamientos de colonización incluido como parte del piloto brasileño Proambiente, programa de política pública para discutir la influencia de variables (por ejemplo, socio-demográficos, económicos y de infraestructura) en el uso de la tierra en la Amazonia brasileña. El artículo concluye que la infraestructura y el crédito rural son importantes en la promoción de diferentes trayectorias de transiciones agroecológicas entre productores de pequeña escala en la Amazonía brasileña.

Palabras clave: uso de la tierra, la economía ecológica, economía agrícola, la agricultura tradicional, la agricultura familiar, transición agroecológica, Cuenca Amazónica. 


\section{INTRODUÇÃO}

A recente publicação do Censo Agropecuário 2006 (IBGE, 2009) deixa claro o papel da produção de pequena escala (agricultura e pecuária familiar, extrativismo e pesca artesanal) para a segurança alimentar, abastecimento do mercado interno e absorção de mãode-obra rural em todas as regiões do Brasil. No Censo Agropecuário 2006 foram identificados 4.367.902 estabelecimentos familiares, o que representa 80,25 milhões de hectares, $84,4 \%$ do número e $24,3 \%$ da área dos estabelecimentos rurais brasileiros. Os resultados demonstram, paradoxalmente, uma estrutura agrária ainda em concentração no país (pois há dez anos, no Censo Agropecuário 1995/1996, a categoria representava 30,5\% da área de plantio) e ao mesmo tempo uma melhoria da eficiência da agricultura familiar (termo usado pelo IBGE, 2009) frente à agricultura de grande escala, pois a primeira registra $38,0 \%$ de participação do Valor Bruto de Produção Agropecuário em 2006 frente a similares 37,9\% em 1996. Mesmo perdendo $6,2 \%$ de seu contingente de terras, a agricultura familiar manteve sua participação produtiva nacional, o que denota sua capacidade de se manter ativa e estratégica na economia rural do país. Outro dado relevante remete-se à sua participação na geração de empregos no campo, pois entre os 16,5 milhões de pessoas empregadas, a agricultura familiar encampa 12,3 milhões $(74,4 \%)$, com média de 2,6 pessoas com mais de 14 anos por estabelecimento rural.
Os resultados acima eram até então inéditos, pois os Censos Agropecuários anteriores não discriminavam categorias de produção rural. Esta nova interpretação dos dados somente se tornou possível após o estabelecimento da Lei da Agricultura Familiar (Lei 11.326 de 2006), que define os conceitos, princípios e instrumentos destinados à formulação das políticas públicas à categoria. Para os efeitos desta Lei, considera-se agricultor familiar aquele que pratica atividades no meio rural, atendendo, simultaneamente, aos seguintes requisitos: (I) não detenha, a qualquer título, área maior do que quatro módulos rurais; (II) utilize predominantemente mão-deobra da própria família nas atividades econômicas do seu estabelecimento ou empreendimento; (III) tenha renda familiar predominantemente originada de atividades econômicas vinculadas ao próprio estabelecimento ou empreendimento; (IV) dirija seu estabelecimento ou empreendimento com sua família. Também são incluídos nesta lei os silvicultores que promovam manejo florestal, aquicultores que explorem reservatórios hídricos de até dois hectares ou tanques-redes de até $500 \mathrm{~m} 3$, extrativistas e pescadores artesanais que atendam os quesitos acima (exceto para o caso dos extrativistas artesanais, que não necessitam atender o quesito I).

Os dados do Censo Agropecuário 2006 permitem observar a diversidade do setor produtivo de pequena escala, assim como suas variações regionais e socioeconômicas, além de permitir a 
reflexão sobre os desafios enfrentados na busca por reconhecimento social, melhor qualidade de vida e intensificação produtiva com baixo impacto ambiental. No entanto, o uso do termo geral "agricultura familiar" para definir o universo analisado pelo Censo Agropecuário 2006 encobre uma grande diversidade de arranjos sociais e sistemas produtivos pertencente ao universo de produtores considerados de pequena escala.

O problema do uso generalizado de categorias sociais como agricultura tradicional ou agricultura familiar em estudos acadêmicos ou em aplicações de políticas públicas é que elas contêm valores histórico-culturais, sociais e simbólicos que tendem a se simplificar, congelar no tempo ou desconsiderar particularidades como diversidade populacional e participação na vida econômica nacional. Muitas vezes, estes termos também são empregados para dicotomizar sistemas produtivos de pequena e grande escala entre passado e modernidade, ou como sinônimo de uma economia de subsistência de pouca relevância econômica. A publicação do Censo Agropecuário 2006 oferece uma oportunidade para refletir sobre a importância do setor produtivo designado como "agricultura familiar" e as implicações do uso deste termo na efetivação de políticas públicas estratégicas de desenvolvimento rural no Brasil.

$\mathrm{O}$ presente artigo traz nas suas duas primeiras sessões uma revisão das definições de agricultura tradicional e agricultura familiar e os

seus papéis sociais, políticos e econômicos. Estas sessões servem de base para uma discussão de políticas públicas de apoio aos sistemas produtivos de pequena escala na Amazônia brasileira. Esta análise é ilustrada nas duas sessões seguintes, uma que apresenta a política pública federal piloto "Proambiente" (que une intensificação produtiva e prestação de serviços ambientais em escala de paisagem rural) e outra que interpreta os dados de 2.400 famílias cadastradas nesta iniciativa de transição agroecológica do setor de pequena escala.

Neste contexto, o artigo pretende salientar três pontos: (a) a agricultura de pequena escala, comumente designada como tradicional e/ou familiar, é diversa e resiliente e não será substituída pela agricultura de grande escala, ao revés, tende a se fortalecer ao longo do tempo, ainda que haja um processo de concentração fundiária e urbanização do país; (b) a ambiguidade dos termos 'agricultura tradicional' e 'agricultura familiar' direciona a uma associação errônea com a 'agricultura de subsistência' (especialmente o primeiro termo), o que induz um foco restrito de políticas públicas sociais a estas categorias, ignorando-se a demanda por investimentos em infra-estrutura em áreas rurais, assim como seus potenciais produtivos e sua contribuição para uma estratégia de desenvolvimento econômico ecológico da nação; (c) os processos de itinerância interna e externa de certos setores da produção de pequena escala podem ser superados com a intensificação dos sistemas 
produtivos, sendo que esse processo pode ser catalisado por políticas públicas adequadas aos diferentes perfis produtivos do setor associadas com obras de infra-estrutura rural e acesso ao crédito rural, ao mercado consumidor e à industria de transformação.

\section{A HERANÇA DO CAMPESINATO}

Se não fosse por frequentes ressurgimentos em discursos de desenvolvimento rural, seria truísmo discutir as distorções da análise proposta por inúmeros autores que examinaram o papel da produção de pequena escala (tradicional ou familiar) dentro da transformação econômica e capitalista mundial. Porém, estas heranças conceituais, tal como a do termo 'camponês' (pea$\operatorname{sant}$ ), emprestado da história européia para o contexto brasileiro, estão longe de desaparecer do discurso popular, político e acadêmico. Alguns autores são emblemáticos nestas definições.

Lênin (1969), em seus estudos sobre o capitalismo na antiga Rússia (século XIX), previu o desaparecimento do campesinato com o desenvolvimento do capitalismo. Sua tese da diferenciação social do campesinato distingue três grupos básicos de camponeses: pobres, médios e ricos. Neste contexto, o desenvolvimento capitalista no campo representa um processo de transformação, ou desintegração, onde uma parcela do campesinato se transformaria em capitalista e outra em assalariada, gerando um processo de proletarização rural e urbana.

Kautsky (1980), em seu estudo sobre o campesinato alemão, defendeu a idéia da inferioridade econômica da agricultura camponesa. $\mathrm{O}$ autor supõe a incompatibilidade entre o progresso técnico e a produção camponesa, sendo que tais estruturas de produção constituiriam um problema para o desenvolvimento da agricultura. Sua tese apresenta elementos que expressam a superioridade da grande exploração agrícola sobre a agricultura de pequena escala, estas com tendência a um processo gradativo de extinção em função de sua baixa capacidade de investimento. Desse modo, a existência da 'agricultura camponesa' no capitalismo se caracterizaria como transitória, onde o excesso de trabalho compensa o seu atraso técnico.

A principal contribuição de Chayanov (1974) para o debate sobre o campesinato foi a construção de uma teoria que identifica o sistema econômico camponês com lógica própria e motivações diferentes daquelas de um empreendimento capitalista. A unidade camponesa é de produção e consumo, portanto, objetiva desencadear não somente processos produtivos, mas também assegurar as necessidades básicas de seus membros. $\mathrm{O}$ modelo de análise chayanoviano utiliza o fator demográfico como variável determinante e independente para explicar a dinâmica social camponesa e o fenômeno da mobilidade.

Na concepção de Chayanov (1974), a dinâmica interna da unidade de produção é determinada pelo número de membros aptos para o trabalho e pelo número de consumidores no lote. A 
composição da família é considerada, portanto, o fator determinante dos processos de decisões da unidade de produção no que diz respeito aos investimentos, ao grau de auto-exploração ou aos diferentes tipos de mobilidade. Porém, além da composição familiar, oportunidades macroeconômicas, mercados urbanos e políticas públicas também determinam processos produtivos e de uso da terra (Abramovay 1999; Brondízio et al. 2002).

Ao avaliar como a categoria abrangente de 'camponeses' tem sido abordada na literatura acadêmica ao longo do tempo, Cancian (1989) diferencia três correntes principais. A primeira refere-se àqueles que salientam a homogeneidade de grupos sociais camponeses, que abrange teóricos que vêem os camponeses como detentores de um sistema sociocultural especial o qual os diferenciam de outros segmentos sociais e os tornam resistentes às inovações. A segunda inclui aqueles que enfatizam a heterogeneidade, que engloba os teóricos que assumem os camponeses como similares a outros setores sociais e ansiosos por mudanças, as quais ocorrem quando oportunidades econômicas aparecem e proporcionam a própria mudança. A terceira corrente inclui aqueles que se voltam mais para as relações históricas dos camponeses com o sistema socioeconômico maior, isto é, como se dá ao longo do tempo a transformação de relativa independência produtiva para a condição de residentes rurais que necessitam vender seus produtos e/ou sua força de trabalho para sobreviver. Para a última corrente, as idéias de Lênin não são inteiramente errôneas, mas também não são totalmente compatíveis com o perfil produtivo rural. Entretanto, ao propor uma reclassificação, Cancian (1989) usa uma combinação de várias das categorias acima para diferenciar a população rural em três distintos perfis: (a) a elite, composta pela classe capitalista, a qual depende do capital e das conexões com a classe capitalista; (b) o proletariado, a qual apresenta poucas chances exceto a venda de sua força de trabalho em troca de salários; (c) a maioria camponesa, a qual detém alta capacidade de produzir seu próprio alimento e que se diferencia em três subclasses: camponeses (peaseants) - pessoas que produzem uma parte substancial de sua alimentação; pequenos produtores de commodity (petty commodity producers) - pessoas que produzem para mercados locais, com baixo investimento de capital e pouco ou nenhum trabalho contratado, além de continuarem a produzir parte de sua alimentação; semi-proletários (semiproletarians) - pessoas que trabalham por salários, mas também dependem da produção própria de alimentos e/ ou de pequenas produções próprias de commodities. Vale lembrar que o autor pontua que essas subclasses não são estáticas, isto é, dependendo de seu contexto externo, o lote rural transita entre as classificações.

$\mathrm{Na}$ sua totalidade, Cancian (1989) e Netting (1989), apoiados em dados da Food and Agriculture Organization of the United Nations (FAO), demonstram que estes setores sociais abrangem por 
volta de $1 / 4$ da população total mundial, representam em torno de $80 \%$ da população rural mundial e vivem em propriedades rurais entre 1-5 hectares, portanto, estão longe de desaparecer como categoria social específica. No mesmo sentido, Roseberry (1993), também baseado em informações geradas pela FAO, ilustra a grande concentração fundiária da América Latina, onde $2 \%$ da população regional controlam $80 \%$ das terras, realidade que no Brasil pouco se modifica, onde 1\% dos proprietários rurais detém a posse de $50 \%$ dos estabelecimentos rurais (IBGE, 2009). Mesmo com todas essas dificuldades (que ilustram relações de poder), o produtor de pequena escala continua a existir, resistir e fazer valer seus modos econômicos de vida rural.

A conceitualização da categoria camponesa tem implicação direta para a diferenciação de termos como agricultura tradicional e agricultura familiar. Para Schneider (2006) e Abramovay (1998), há uma distinção fundamental entre agricultores tradicionais e familiares. Segundo os autores, enquanto os agricultores tradicionais podem ser entendidos como 'sociedades parciais com uma cultura parcial, integrados de modo incompleto a mercados imperfeitos', que representam um modo de vida caracterizado pela personalização dos vínculos sociais e pela ausência de uma contabilidade formal nas operações produtivas, a agricultura familiar seria 'integrada ao mercado, capaz de incorporar avanços técnicos e responder às políticas governamentais'. Aquilo que era antes de tudo um modo de vida converteu-se numa profissão, numa forma de trabalho. Desta forma, a diferenciação proposta pelos autores entre agricultores tradicionais e familiares é mais analítica que propriamente empírica.

Van Der Plog (2006) utiliza o termo 'pequena produção mercantil' para designar o sistema de produção que visa à comercialização parcial ou total de seu produto, entretanto, onde a força de trabalho e outros recursos (ex: terra e recursos naturais) não entram no processo de trabalho como mercadorias, pois detém valores de uso, além do valor de troca. $\mathrm{Na}$ 'produção simples de mercadoria' há uma mudança decisiva em relação à 'pequena produção mercantil': com exceção do trabalho, os demais recursos materiais e sociais entram no processo produtivo como mercadorias, portanto, elas introduzem não apenas as relações mercantis, mas também a 'lógica de mercado' no processo de trabalho. A 'produção capitalista de mercadorias' representa uma mercantilização completa: a força de trabalho e os demais recursos entram no processo como mercadorias. Baseado nesses conceitos e nas definições propostas acima por Schneider (2006) e Abramovay (1998), a produção tradicional se caracterizaria como 'pequena produção mercantil', enquanto a produção familiar se assemelharia mais à 'produção simples de mercadoria'. Portanto, os 'agricultores tradicionais' são apenas parcialmente integrados aos mercados imperfeitos e avançam nessas relações para um sistema de 'agricultura familiar'. A noção 
de intensificação das relações mercantis pode ajudar a distinguir as formas e os graus em que as produções tradicionais e familiares são constituídas enquanto relação mercantil.

Brondízio \& Siqueira (1997) e Netting (1993), por outro lado, evitam a distinção entre agricultores tradicionais e familiares, ou mesmo a utilização do conceito de "camponês". Para os autores, a produção de pequena escala se notabiliza como um tipo de população rural que se funda sobre a relação entre família, trabalho, terra e mercado consumidor, que inclui a produção para o consumo e também para mercados locais, regionais, nacionais e internacionais, com mais intensidade entre um ou outro foco conforme as oportunidades externas às propriedades rurais se configuram. Sua economia de vida depende de trabalho familiar, porém, em determinadas circunstâncias, se necessário, empregam trabalho externo remunerado para conferir maior escala à produção e acessar o mercado consumidor. A categoria também não é específica de um momento da história ou de uma área geográfica, pois existe antes do sistema capitalista e irá existir depois em diferentes partes do mundo. Como categoria social, não está fadada a desaparecer, além de não se constituir como um grupo homogêneo. Logo, a diversidade social, cultural e ecológica dessa categoria precisa ser reconhecida em políticas públicas de desenvolvimento econômico de áreas rurais e em análises acadêmicas. Em oposição ao demonstrado acima, aqui a atenção é na diversidade social que emerge da análise empírica e não na divisão por categorias analíticas.

Portanto, vimos em Van Der Plog (2006), Schneider (2006) e Abramovay (1998) distinções entre agricultura tradicional e agricultura familiar, ao passo que Brondízio \& Siqueira (1997), Netting (1993) e, de certa forma, Cancian (1989) chamam atenção por um lado, para o gradiente de diversidades socioculturais e econômicas, e por outro, pelas semelhanças nos desafios que enfrentam enquanto produtores de pequena escala. Apesar de contradições reais e às vezes semânticas entre essas diferentes abordagens, todos concordam que, tradicional ou familiar, o produtor de pequena escala evidencia sua relevância social. Porém, o que fica claro é que as diferenciações teóricas entre agricultura tradicional ou agricultura familiar, ainda que tragam uma possível contribuição analítica para a academia e categorias convenientes para políticas públicas, representam um universo muito mais complexo de se observar do ponto de vista empírico ou na realidade de campo.

\section{A AGRICULTURA DE PEQUENA ES- CALA NO CONTEXTO BRASILEIRO: SUA IMPORTÂNCIA SOCIAL, POLÍ- TICA E ECONÔMICA}

No Brasil, a construção de um espaço rural se efetuou, e assim continua, na maioria dos casos, sob o signo da precariedade estrutural, que o torna incapaz de desenvolver todas as potencialidades do próprio sistema de produção e de vida social e cultural (Wanderley 
2001). É preciso considerar que o modelo original da população rural brasileira reflete as particularidades dos processos sociais do período colonial e da própria história da agricultura brasileira: a dominação econômica, social e política da grande propriedade, a marca cruel da escravidão e a existência de uma enorme fronteira de terras livres passíveis de serem ocupadas pela simples ocupação e posse. O sistema de produção de pequena escala brasileiro tem sido marcado historicamente pela ausência de incentivos econômicos, infra-estrutura de produção e oferta de serviços básicos que permitam desenvolvimento econômico, reinvestimento local e melhorias na qualidade de vida em zonas rurais. A história de vários segmentos da população rural brasileira pode ser definida como o registro das lutas para conseguir espaço na economia e na sociedade.

A agricultura familiar não é uma categoria social recente, nem a ela corresponde uma categoria analítica nova na economia agrícola e na sociologia rural. No entanto, a utilização do termo, com o significado e a abrangência que lhes têm sido atribuído nos últimos anos no Brasil, assume ares de novidade e renovação. Fala-se de uma agricultura familiar como uma nova personagem, que diferente do "camponês tradicional," vem assumindo sua condição de produtor que se moderniza. Propõem-se políticas públicas para estimulá-la, fundadas em tipologias que se baseiam em uma viabilidade econômica e social diferenciada. Mas, afinal, o uso do termo agricultura familiar vem sendo feito de maneira diferente de outros como caboclo, colono, campesinato, agricultura de subsistência ou pequeno produtor, categorias que, até então, circulavam com mais frequência em esferas acadêmicas e populares?

A agricultura familiar é um conceito genérico, que incorpora uma diversidade de situações específicas. A agricultura familiar que se reproduz nas sociedades modernas deve adaptar-se a um novo contexto socioeconômico, que a obriga a realizar modificações importantes na forma de produção, vidas sociais e dinâmicas demográficas. Essas transformações, no entanto, não produzem uma ruptura definitiva com as formas anteriores. As populações rurais brasileiras têm características particulares que resultam de situações próprias da história social de diferentes regiões do país e que servem de fundamento a esse patrimônio sociocultural, que aos poucos vem se adaptando e contribuindo para as transformações da sociedade brasileira moderna, inclusive mantendo fortes ligações com as zonas urbanas.

O ponto de partida é o conceito de agricultura familiar entendida como aquela em que a família, ao mesmo tempo em que é a proprietária dos meios de produção, assume o trabalho no estabelecimento produtivo. É importante insistir que esse caráter familiar, variável em tipo e grau, não é um mero detalhe superficial e descritivo, ou seja, o fato de uma estrutura produtiva associar em diferentes graus família, produção, consumo e trabalho próprio e/ou contratado tem conse- 
quências fundamentais para a forma como ela age econômica e socialmente (Lamarche 1994), o que demanda estratégias diferenciadas na estruturação de políticas públicas para este setor produtivo.

A diversidade de sistemas produtivos, a integração e relevante contribuição aos mercados consumidores nacionais e a garantia de produção para consumo e emprego são preocupações fundamentais para a constituição do que estamos aqui chamando de patrimônio sociocultural da agricultura familiar brasileira. A esse respeito, parece claro que a referência a uma agricultura de subsistência, tão frequente na literatura especializada, pode esconder os propósitos mais profundos dos agricultores familiares. Nada indica que se restrinjam, em seus objetivos, à simples obtenção direta da alimentação familiar, o que só acontece quando as portas do mercado consumidor estão efetivamente fechadas para eles. Esse contexto é indissociável e consequente de um processo histórico que estruturou a agricultura brasileira em grandes propriedades patronais, restando à agricultura familiar a atribuição de "amansar a terra" nas fronteiras agrícolas. Entretanto, quando os instrumentos econômicos públicos e as oportunidades de mercado se voltam para a agricultura familiar, seus potenciais de elevação da produtividade da terra e do trabalho se evidenciam mais rapidamente. Particularmente na Amazônia, com a chegada concomitante de agricultores familiares e patronais, se confere aos primeiros, apesar de largamente invisível até a publica- ção do Censo Agropecuário 2006, um papel fundamental para a segurança alimentar e abastecimento do mercado interno local, regional, nacional e internacional.

Conforme frisa Guanziroli et al. (2001), com técnicas modernas e uso relativamente mais intenso do ativo de produção trabalho quando comparado à agricultura de grande escala, a agricultura familiar é capaz de gerar uma renda líquida superior ao custo de oportunidade de seu trabalho. Daí a pertinência da abordagem de Schultz (1965) quanto à necessidade de se estabelecer processos gradativos de mudança de uso da terra, com tecnologias adaptadas ao contexto de escassez do ativo trabalho. Mas para que esses processos ocorram, o país necessita assumir a agricultura de pequena escala como prioridade de política estratégica de desenvolvimento econômico ecológico, e não meramente como foco de política social compensatória.

Adicionalmente, a agricultura de pequena escala é ao mesmo tempo sensível e resiliente às condições do meio ambiente. Os agricultores familiares, ao dispor em geral de poucos recursos externos que possibilitem a transformação radical do meio ambiente $e$ sua adaptação às exigências do mercado consumidor, ajustam seus esforços às restrições do meio ambiente. Neste sentido, enquanto a agricultura de larga escala tende a transformar o meio ambiente para adequá-lo às suas condições de produção, a agricultura familiar tende a alocar seus recursos mais escassos (trabalho e capital) para 
melhor aproveitar as determinantes derivadas das condições ambientais. Isso não quer dizer que as respostas sejam sempre sustentáveis. É o caso do sistema de corte e queima, cuja sustentabilidade exige a possibilidade de rotação longa, suficiente para permitir a recomposição da floresta e a (re)fertilização do solo pela incorporação de matéria orgânica produzida pelas capoeiras (Guanziroli et al. 2001).

Uma dimensão importante para a agricultura de pequena escala é a constituição de um território familiar, um lugar de vida e de trabalho, capaz de guardar a memória da família e de reproduzi-la para as gerações posteriores na forma de landesque capital (Brookfield 2001). Paradoxalmente, a perseguição desse objetivo supõe, certas vezes, a mobilidade do agricultor, que se submete a longos e sucessivos deslocamentos espaciais.

Romeiro (1998) argumenta que a dinâmica de uso da terra de parte dos agricultores familiares amazônicos é marcada pela lógica produtiva duplamente itinerante: itinerância interna e itinerância externa. Itinerância interna porque a grande maioria dos produtores tem a floresta como fonte principal de nutrientes para as culturas de ciclo curto. O processo de derruba e queima é o mecanismo pelo qual muitos agricultores obtêm os nutrientes que precisam por dois ou três anos de lavouras numa área que varia geralmente de 0.5 a 5 hectares. Considerando uma área média disponível de 40 hectares de floresta, um agricultor levaria, nestas condições, entre 20 a 30 anos para fazer a rotação completa do terreno, o que seria sustentável do ponto de vista ecológico, pois 25-30 anos é o período necessário para a regeneração da biomassa florestal. No entanto, o processo de pecuarização em curso nos últimos anos e o consequente aumento da área de pastagens (em áreas de regeneração natural pós corte e queima) vem tornando cada vez menos sustentável esta prática. O encurtamento do período de pousio para a recuperação da biomassa florestal é um fato generalizado. Nas regiões de colonização mais antiga, a maioria dos agricultores obtém os fertilizantes necessários queimando não mais florestas maduras, mas capoeiras resultantes de um período de pousio que em algumas localidades já se reduziu a três ou quatro anos (cerca de um décimo do tempo que seria necessário para manter a viabilidade produtiva). A crescente insustentabilidade destas práticas agrícolas na região leva parte destes agricultores familiares a se juntar com o afluxo de migrantes de outras regiões em busca de novas terras, que resulta na itinerância externa. Por vários motivos, a criação de gado é um objetivo primordial da estratégia de acumulação destes produtores familiares (Hecht 1993). De modo geral, o gado resulta em uma produtividade do trabalho e garantia de fluxo monetário mais estável e superior às proporcionadas pelas lavouras anuais.

A consolidação da agricultura familiar numa fronteira agrícola demanda um processo de intensificação do uso da terra e de capitalização baseada em sistemas produtivos diversos com ba- 
lanço entre cultivos anuais, cultivos perenes e pecuária. De maneira geral, quando a fase de expansão produtiva baseada no sistema de corte e queima encontra seus limites, a fase seguinte seleciona agricultores capitalizados (baseados em sistemas diversificados compostos por cultivos anuais, perenes e pecuária) que não irão compor um novo processo de itinerância externa, e agricultores descapitalizados (baseados em sistemas mais simplificados, sobretudo, agricultura anual de corte e queima) com demanda de nova itinerância externa, pois seus solos se esgotam e a terra disponível não é mais suficiente, do que resulta, frequentemente, o deslocamento progressivo para outras áreas, onde recomeçarão novo ciclo. Como lembra Guanziroli et al. (2001), muitas vezes o esgotamento do potencial produtivo da terra não ocorre devido ao sistema de corte e queima, que se tiver áreas suficientes de regeneração causa impactos mínimos em comparação à agricultura química e mecanizada, mas devido ao adensamento populacional e consequente uso sucessivo que pressiona para utilização de áreas de pousio (capoeiras), sobretudo, com a introdução da pecuária extensiva, minando a capacidade dos solos de restabelecer seu potencial produtivo.

Como salienta Moran (2009), o método de corte e queima para a preparação da terra representa um modo sensato e barato para obter produtos vitais em regiões de baixo rendimento agrícola somente quando praticado a baixas densidades populacionais. Florestas de quase todas as regiões do mundo so- freram ciclos de corte e queima que só se tornaram destrutivos e improdutivos quando as terras em pousio diminuíram devido à pressão populacional, e a restauração natural não era suficiente para completar um ciclo adequado de crescimento da vegetação secundária. Sendo assim, o processo de envelhecimento de uma fronteira agrícola demanda a eliminação da prática de corte e queima, a diversificação e a intensificação produtiva para permitir processos de capitalização. Mas há de se ter o cuidado na interpretação do significado do termo "intensificação produtiva".

Denevan \& Padoch (1987), citados por Brondízio \& Siqueira (1997), também corroboram Moran (2009) quando reelaboram a falsa ideia do período longo de pousio como algo necessariamente improdutivo ou pouco intensivo. Conforme os autores, se os sistemas agrícolas baseados em insumos químicos e mecanização limitam a capacidade produtiva da terra no longo prazo, podem ser considerados mais extensivos que intensivos e temporalmente insustentáveis em relação ao sistema de corte e queima, que rotaciona o uso da terra visando recuperar sua capacidade produtiva e suas propriedades naturais. Ademais, outro tipo intensivo característico de uso da terra pela agricultura familiar refere-se aos sistemas agroflorestais, que nas suas diferentes composições simulam as funções das florestas nativas, mas têm sido invisíveis para muitos pesquisadores que empregam parâmetros analíticos convencionais, assim como para os tomadores de de- 
cisões sobre políticas agrícolas para a agricultura de pequena escala.

Com pertinência, Netting (1993) lamenta o fato de que o termo intensificação tem sido usado como um conceito elusivo e automaticamente associado à modernização, alta produtividade, eficiência e adaptabilidade de sistemas produtivos. $\mathrm{O}$ autor não somente redefine intensificação à luz da sustentabilidade e produtividade, mas também critica o mito de que a agricultura familiar é improdutiva. E como ponderam Brondízio \& Siqueira (1997), a intensificação não é um processo linear e dependente somente de um fator (ex: crescimento populacional ou alta demanda de mercado consumidor), mas um processo que reflete o balanço entre as condições presentes da interação planta-solo, eventos socioeconômicos passados e desenvolvimento de práticas de manejo que motivam a mudança de uso da terra do presente ao futuro.

Porém, como estabelecer a transição do sistema produtivo impactante e itinerante para o sustentável e permanente? E quais as variáveis mais determinantes nos processos decisórios sobre usos da terra e dos recursos naturais no âmbito local que poderiam basear políticas públicas para o setor de pequena escala? Van Wey et al. (2009) sustenta que quase todos os modelos que postulam simplificação de fatores determinantes das mudanças de uso e cobertura da terra têm sido rejeitados por pesquisas empíricas bem fundamentadas. As autoras dividem as teorias sobre o tema em dois grupos: o primeiro daqueles que postulam uma relação unidirecional e determinística entre um conjunto de variáveis independentes (geralmente macro-estruturais) e o uso da terra, e o segundo dos que atribuem expediente aos atores individuais à medida que esses causam mudanças no uso da terra. Duas conclusões foram obtidas: a escala e o nível de análise são importantes, assim como o contexto local, pois as relações que existem em uma escala frequentemente inexistem em outras, porém, nem todas as teorias são aplicáveis em escalas múltiplas. Um bom exemplo do contexto é a institucionalidade presente em cada local, que pode direcionar o uso da terra e dos recursos naturais em diferentes níveis economicamente produtivos e de qualidade ambiental.

\section{PROAMBIENTE}

Os principais movimentos sociais $\mathrm{da}$ Amazônia brasileira estabeleceram um debate com mais de 20 mil lideranças rurais locais, entre os anos 2000 e 2002, na busca de alternativas e estratégias econômicas ecológicas para superação do processo histórico de itinerância interna e itinerância externa de famílias rurais. Dessa intensa iniciativa popular e democrática surge a proposta denominada de Programa de Desenvolvimento Socioambiental da Produção Familiar Rural (Proambiente), incorporada como política pública piloto, a partir de 2003, no primeiro ano do Governo Lula. Basicamente, o Proambiente propõe unir quatro ações: participação social na política pública (conselho consultivo entre go- 
verno federal e movimentos sociais), planejamento territorial (identificação do contexto político e de oportunidades econômicas locais), planejamento econômico ecológico dos lotes rurais (planejamento individual de uso da terra e dos recursos naturais) e acordos comunitários de serviços ambientais (aplicação de métodos participativos de conhecimento do meio, acordos comunitários, resolução de conflitos e sanções graduais para prestação de serviços ambientais em escala de paisagem rural).

Inicialmente, o Proambiente foi planejado para ser executado em 12 regiões pioneiras (tendo em torno de $500 \mathrm{fa}-$ mílias cada, totalizando 6.000 famílias) com experiência na implementação de projetos de transição agroecológica. Entre essas 12 regiões, dez são formadas por agricultura e pecuária familiar, uma por pesca artesanal e uma por povos indígenas. Em 2005, dois anos depois do início do Proambiente como política pública piloto, os resultados evidenciavam os primeiros sinais das diferenças institucionais no que se refere à formação de capital social. Entre as dez regiões formadas por agricultura e pecuária familiar, sete geraram os resultados esperados (planejamento econômico ecológico dos lotes rurais e acordos comunitários de serviços ambientais), sendo que as demais regiões de agricultura e pecuária, a região de pesca artesanal e a região de povos indígenas ficaram aquém dos passos planejados. O que ficou evidente é que apesar de todas as regiões selecionadas serem enquadráveis nos critérios da Lei da Agricultura Familiar, elas apresentam diferenças locais que demandam ações específicas. No caso das regiões de agricultura e pecuária familiar, havia a demanda de fortalecimento das organizações sociais, pois suas experiências em projetos de transição agroecológica não foram suficientes para gerenciar uma política pública com a complexidade do Proambiente. No caso particular da região de pesca artesanal, faltava conhecimento suficiente da equipe governamental para tratar das especificidades da categoria, dificuldade que foi superada a partir de 2005. No caso da região de povos indígenas, conflitos internos da categoria impediram a consolidação do programa.

Nesse sentido, o presente artigo analisa os dados gerados pelas sete regiões de agricultura e pecuária familiar com capital social mais consolidado (ou seja, experiência na execução de projetos governamentais e não governamentais e participação em associações comunitárias), sendo elas, Transamazônica (PA), Rio Capim (PA), Bico do Papagaio (TO), Baixada Maranhense (MA), Noroeste (MT), Ouro Preto D'Oeste (RO) e Alto Acre (AC). Mesmo com as suas similaridades em capital social, essas regiões também apresentam particularidades locais que não podem ser ignoradas por políticas públicas. O estudo de Mattos (2010) identificou as variáveis independentes mais determinantes para os processos de transição agroecológica, baseado na análise de dados de 2.400 famílias selecionadas pelo Proambiente nestas sete regiões. A seguir, os resultados do autor são 
apresentados de forma sumarizada.

\section{ASPECTOS FUNDAMENTAIS DA TRANSIÇÃO AGROECOLÓGICA NA AMAZÔNIA BRASILEIRA}

A discussão sobre a transição agroecológica está hoje bastante generalizada e diz respeito à ampliação da sustentabilidade de longo prazo dos mais distintos sistemas agrícolas. São diversas as fontes de conhecimento que podem amparar processos de transição agroecológica, entre outras, a pesquisa científica, os conhecimentos locais empíricos e o aprendizado acumulado na prática de construção de grande variedade de sistemas sustentáveis (Mattos et al. 2006).

Conforme frisam Gliessman (2000) e Mattos et al. (2006), a transição agroecológica passa por diversas etapas, dentro e fora do sistema de produção, dependendo de quanto distam dos objetivos do manejo agroecológico. Quanto à "transição interna ao sistema produtivo", os autores destacam "a eliminação do uso do fogo e a redução e racionalização do uso de insumos químicos", "a substituição de insumos químicos por orgânicos" e "o redesenho dos sistemas produtivos e o manejo da biodiversidade". Já em relação à "transição externa ao sistema produtivo", alertam que a transição agroecológica não pode edificar-se unicamente baseada em tecnologias. Embora as mudanças tecnológicas sejam fundamentais, a transição agroecológica só poderá ser alcançada quando outras condições externas à unidade de pro- dução estiverem estabelecidas. Assim, há um conjunto de condições a ser construído pela sociedade e pelo Estado, como a expansão da consciência pública, a organização dos mercados consumidores, as mudanças na pesquisa, ensino e extensão, a disponibilização de infra-estrutura (de transporte, energia elétrica, comunicação, educação, saúde), a formulação de políticas públicas com enfoque agroecológico e as inovações na legislação ambiental. A transição interna aos sistemas de produção também não teria sentido sem uma mudança institucional nos padrões de desenvolvimento, como políticas de crédito adaptadas ao contexto agroecológico.

Prestar atenção nas particularidades da transição agroecológica e nos distintos sistemas produtivos que dela emergem dão apoio para o fortalecimento da agroecologia. A elaboração de tipologias analíticas ajudam a interpretar a diversidade da agricultura familiar e a compreender as distintas formas $\mathrm{e}$ condições de transição produtiva possíveis para cada contexto local.

Costa (2000) critica a noção de que a agricultura familiar apenas "amansa a terra" e prepara o terreno para as fazendas de gado e os plantios de commodities exportáveis de grande escala que se seguem na fronteira agrícola. Nessa perspectiva, são reproduzidas as formas de evolução da fronteira agrícola em que as frentes da agricultura familiar em sistema de "corte e queima" esgotam suas possibilidades em uma área para, em seguida, se reproduzir em outra, sendo substituída nas 
áreas antigas por formas capitalistas de produção, as quais, ao assimilar o trabalho ali incorporado, procede uma nova acumulação primitiva. Nessa lógica, no entanto, os limites para a formação de capital mostram-se absolutos ao bloquear processos de mudanças e inovações que rompem com os padrões da agricultura familiar itinerante de pousio longo.

Como discute Carvalho (2000), quando questiona a noção de que a agricultura familiar apenas cumpre papel de "amansar a terra", desde a década de 80, processos alternativos de inovação tecnológica e de mudanças qualitativas de uso da terra vêm ocorrendo na agricultura de pequena escala da Amazônia brasileira. Há um esforço claro do setor de produção familiar rural de romper o padrão de itinerância interna e externa por meio de reordenação de sua base produtiva. Os dados da autora ainda revelam que aos sistemas de produção mais complexos correspondem os níveis de renda mais elevados, sendo que estão condicionados a variáveis internas e externas.

As variáveis internas que fundamentam as mudanças de uso da terra das famílias rurais incluem fatores socioculturais, trajetórias de vida, demografia familiar, capacidade interna de trabalho, nível de escolaridade, organização social, fatores ambientais como disponibilidade de recursos naturais e contextuais como localização e distância de mercados consumidores. As variáveis externas são aquelas desencadeadas por instituições públicas, de classe e comunitárias, e que envolvem acesso às técnicas e tecnologias agrícolas, ao crédito rural, à infra-estrutura, aos serviços públicos básicos e às formas coletivas de organização do trabalho.

Os sistemas de produção familiar caracterizados por cultivos anuais e perenes somados à pecuária ilustram a diversificação produtiva que visa minimizar riscos e atender diferentes oportunidades de mercado. Os sistemas agroflorestais e agrosilvipastoris são os mais representativos para ilustrar a transição agroecológica da agricultura familiar amazônica.

O presente estudo segue a classificação tipológica traçada por Romeiro (1998) e Mattos (2010). No início da ocupação do lote, as lavouras anuais para consumo e renda (tipo 1: culturas anuais) têm o papel de preparar o terreno para a abertura das áreas de pastagens (tipo 2: culturas anuais + pecuária), o que resulta num processo contínuo de desmatamento da reserva legal e substituição da caça pela pecuária como fonte de proteína animal. A criação de gado caracteriza-se também como uma estratégia de acumulação, pois proporciona rendimento mais estável e superior às culturas anuais, e com sua alta liquidez, transforma-se numa "poupança viva". Anos depois, a alternativa deve ser o investimento em culturas perenes (tipo 4: culturas anuais + culturas perenes + pecuária), porém, o alto investimento, a quantidade de horas demandadas e o longo prazo para viabilização econômica esbarram no baixo capital de giro disponível e na baixa capacidade de trabalho dos lotes. Assim, a passagem do tipo 
2 para o tipo 4 se viabiliza mais facilmente se houver aporte de políticas de crédito rural sob condições adequadas de carência, amortização e juros, caso contrário, a família permanece no tipo 2 ou estabelece processos gradativos para o tipo 4. Trajetória diferente pode ocorrer em lotes de tamanho reduzido, que como têm na pecuária familiar uma atividade economicamente inviável, transitam diretamente do tipo 1 ao tipo 3 (culturas anuais + culturas perenes) por meio de complementação do sistema de cultivos anuais com cultivos perenes. E se houver esgotamento das capoeiras e impossibilidade de convivência entre culturas anuais e gado (tipo 2), a família pode optar pelo tipo 5 (pecuária extensiva - sem manejo de pastagens), enquanto outras aderem diretamente ao tipo $5 \mathrm{em}$ pouco tempo de ocupação do lote (0-5 anos) devido ao seu perfil pecuário.

Pichón (1996), apoiado nos índices de Chayanov (1923), observou que muitos colonos praticavam sistema misto compostos por plantas anuais, perenes e pecuária (tipo 4 sugerido por Romeiro, 1998) como forma de intensificar e diversificar o uso da terra. Primeiramente, mais terras eram convertidas em pastagens, para em seguida serem introduzidas espécies frutíferas, ao passo que a área destinada ao cultivo de anuais mantinha-se estável. Logo, o primeiro processo de capitalização vem com a introdução da pecuária e o segundo com as culturas perenes.

Romeiro (1998), ao correlacionar as variáveis "tempo de ocupação do lote", "tipologias de uso de terra" e "renda familiar anual", de forma geral (sem desconsiderar as exceções), obteve a seguinte associação: o tipo 1 (culturas anuais) encampa agricultores descapitalizados, locados em nova fronteira agrícola e que têm a mandioca como principal fonte de renda monetária, sendo que o perfil estocável do produto o faz também cumprir papel de poupança; o tipo 2 (culturas anuais + pecuária) abrange agricultores com perspectivas de capitalização, lotados em nova fronteira agrícola e que têm o gado de corte como principal fonte de renda monetária, sendo que onde há acesso ao transporte para escoamento de produção, a introdução do gado também pode incrementar o sistema de produção de culturas anuais; o tipo 3 (culturas anuais + culturas perenes) é caracterizado por agricultores com perspectivas de capitalização, assentados tanto em nova fronteira agrícola como em regiões mais consolidadas e que tem os cultivos perenes como principal fonte de renda monetária, sendo que sua introdução se dá em áreas de pousio anteriormente cultivadas com culturas anuais, numa estratégia de enriquecimento de capoeiras; o tipo 4 (culturas anuais + culturas perenes + pecuária) apresenta agricultores capitalizados, de regiões mais consolidadas e que não têm um produto específico como principal fonte de renda monetária devido à adesão aos sistemas diversificados, sendo que a capacidade de trabalho do lote e os incentivos fiscais, principalmente associados ao crédito rural, cumprem papel importante na introdução da pecuária e, sobretudo, cultivos perenes; o tipo 5 (pecuária 
extensiva - sem manejo de pastagens) notabiliza-se por agricultores capitalizados e agricultores com perspectivas de capitalização, localizados tanto em nova fronteira agrícola como em regiões mais consolidadas.

Mattos (2010), em estudo sobre o Proambiente, encontrou dados similares aos apresentados por Romeiro (1998). O tipo 1 (culturas anuais) registra lotes principalmente com tempo de ocupação de 0-5 anos e rendas baixas (até US\$ 3 mil ao ano), o tipo 3 (culturas anuais + culturas perenes) sobretudo com tempo de ocupação de 0-5 anos (embora não sejam desprezíveis tempos mais longos) e rendas intermediárias (entre US\$ 3 e 6 mil ao ano), e o tipo 5 (pecuária extensiva - sem manejo de pastagens) mais comumente com tempo de ocupação de 0-5 anos e rendas intermediárias (entre US\$ 3 e 6 mil ao ano). Já o tipo 2 (culturas anuais + pecuária) apresenta evolução crescente do número de lotes ao longo do tempo e rendas baixas para altas (desde US\$ 1 mil até mais de US\$10 mil ao ano), enquanto o tipo 4 (culturas anuais + culturas perenes + pecuária) se notabiliza em lotes com tempo de ocupação entre 5-10 e 10-20 anos e as rendas mais altas entre todos os tipos comparados (desde US\$ 2 mil até mais de US\$ 10 mil ao ano).

Portanto, o tempo de ocupação do lote é uma variável independente importante para a tipologia de uso da terra, não somente devido à evolução da composição familiar e aumento de sua capacidade de trabalho, mas também porque consolida, gradativamente, o processo de capitalização conforme se desencadeia a diversificação produtiva agroecológica. Já o acesso a fontes externas de capital (ex: crédito rural, infra-estrutura de transporte e energia, programas governamentais de transferência de renda, previdência rural e renda extra não agrícola) ajudam a catalisar esse processo.

Mattos (2010) traça a relação entre "origem do chefe de família" e "tipologias de uso da terra", com o devido cuidado para não dar um enfoque determinista ao estudo, e demonstra que existe uma forte associação entre ambos. Somente agricultores familiares locados na Amazônia com origem no Norte e Nordeste do país ainda permanecem de forma estatisticamente significativa nos tipos menos diversificados de uso da terra (1, 2, 3 e 5). O tipo 1 (culturas anuais) gira em torno de um décimo dos lotes de nordestinos $(10,40 \%)$ e nortistas $(8,81 \%)$, o tipo 2 (culturas anuais + pecuária) é o segundo mais frequente para ambas origens (27,52\% e $26,92 \%$, respectivamente), o tipo 3 (culturas anuais + culturas perenes) tem presença maior de famílias amazônicas $(20,37 \%$ versus $4,40 \%)$ e o tipo 5 (pecuária extensiva - sem manejo de pastagens) tem quase o dobro de nordestinos (3,42\% versus $6,06 \%)$. No entanto, apesar da importância dos tipos anteriores, o tipo 4 (culturas anuais + culturas perenes + pecuária) já é o mais frequente para os originários do Norte e Nordeste, mas em percentual inferior de lotes, 38,89\% e 53,21\%, respectivamente, que os de agricultores familiares oriundos do Centro- 
-Oeste $(71,93 \%)$, Sudeste $(72,03 \%)$ e Sul $(84,50 \%)$. Os dados também evidenciam que os perfis produtivos dos nordestinos e nortistas têm trajetórias tipológicas e processos de capitalização mais lentos quando comparados aos produtores familiares do Centro-Oeste, Sudeste e Sul.

Estudos de Van Wey et al. (2007), Brondízio et al. (2002), Perz \& Walker (2002), McCracken et al. (1999) e Brumer (2001) traçam um modelo conceitual baseado em uma sequência entre "índice de geração" (relação entre potencial de trabalho e demanda de consumo dos lotes) e uso da terra. Os autores classificam como estágio I (tempo de ocupação do lote inferior a cinco anos) aquele que envolve pais jovens, crianças pequenas, baixa demanda de consumo e baixa capacidade de trabalho, o que incentiva o cultivo de anuais e ausência de áreas de regeneração de capoeiras; o estágio II (tempo de ocupação do lote em torno de cinco anos) demonstra pais jovens com crianças em crescimento, o que gera cultivo de anuais, cultivo de perenes jovens, início da formação de pastagens e poucas áreas de regeneração de capoeiras; o estágio III (tempo de ocupação do lote por volta de dez anos) com pais mais velhos e adolescentes, com declínio na ênfase aos cultivos anuais, prioridade à atividade pecuária e aumento de área de regeneração de capoeiras; o estágio IV (tempo de ocupação do lote de aproximadamente 15 anos) evidencia pais mais velhos, jovens adultos e predominância de cultivos perenes e atividade pecuária, com estabilização da área de regeneração de capoeiras; o estágio V (tempo de ocupação do lote após 20 anos) traz uma situação em que a presença de múltiplas gerações levou a um perfil produtivo altamente voltado para os cultivos anuais, cultivos perenes e pecuária, além de diminuição das áreas de regeneração de capoeiras.

Dados obtidos por Mattos (2010) demonstram que lotes com "índice de geração" intermediário (equilíbrio entre potencial de trabalho e demanda de consumo) ainda têm presença significativa de cultivos anuais (tipo 1) ou cultivos anuais e perenes (tipo 3), mas quando há elevação do índice de geração (maior potencial de trabalho em relação à demanda de consumo) também eleva-se a participação de lotes com cultivos anuais e pecuária (tipo 2) e, principalmente, com sistemas mistos de culturas anuais, perenes e pecuária (tipo 4).

Os dados de Mattos (2010) também evidenciam a importância do "índice de gênero" (relação ente trabalho masculino e de trabalho total) na diversificação produtiva dos lotes. Lotes com baixo índice de gênero (mais trabalho masculino em relação ao trabalho total) possuem contingentes expressivos de cultivos anuais e pecuária (tipo 2), ao passo que lotes com índice de gênero intermediários (trabalho masculino equilibrado ao trabalho feminino) desencadeiam diversificação menos (tipo 3: cultivos anuais + cultivos perenes) ou mais (tipo 4: cultivos anuais + cultivos perenes + pecuária) intensas de sistemas produtivos, processo que irá depender também do tamanho do 
lote (a ser discutido adiante). Portanto, Mattos (2010) observa que existe forte relação entre (a) trabalho masculino e pecuária e (b) trabalho feminino e culturas perenes, resultados similares aos encontrados por Van Wey et al. (2007) e Pan et al. (2004).

Mattos (2010) ainda demonstra que a "escolaridade" masculina e feminina mais baixa (analfabetos/as ou $1^{\mathrm{a}}$ a $4^{\mathrm{a}}$ séries) tende a puxar o uso da terra para o tipo 1 (culturas anuais), sendo que a elevação da mesma impõe condições mais propícias para se alcançar o tipo 2 (cultivos anuais + pecuária) e, principalmente, o tipo 4 (cultivos anuais + cultivos perenes + pecuária), que gera processos mais intensos de capitalização. Não por acaso, na análise comparativa de variáveis independentes foi obtida a relação positiva entre escolaridade e renda familiar anual.

McCracken et al. (2002) e Perz (2001) traçam uma relação relevante entre "evolução do ciclo produtivo", "demanda de capital e trabalho" e "tamanho do lote". No início da ocupação do lote, os pais jovens empregam culturas anuais, as quais demandam considerável quantidade de trabalho para corte da floresta primária, coivara, queima, plantio, cultivo e colheita, mas por outro lado, requerem menor quantidade de terra e capital, além de representarem uma estratégia de baixo risco econômico. Ao longo do tempo de ocupação do lote, um estoque de terras desmatadas se acumula a tal ponto que se tornam inadequadas para a produção de cultivos anuais, desta feita, entra a importância do crédito rural e da renda familiar, assim como da diversificação de oportunidades do mercado consumidor, para orientar a introdução de cultivos perenes e da atividade pecuária. $\mathrm{O}$ cultivo de perenes envolve maior demanda de trabalho e capital, mas não necessariamente um alto contingente de terra. Já a introdução de pastagens e animais de criação caracteriza-se como reserva de capital (ou uma poupança viva) e demanda maiores quantidades de terra e menor intensidade de capital e trabalho.

Em estudo de Costa (2000), quatro combinações são exibidas quanto à abundância ou restrição de trabalho e terra: lotes com (a) restrição de trabalho e abundância de terra (nova fronteira agrícola), (b) abundância de trabalho e terra, (c) restrição de trabalho e terra e (d) abundância de trabalho e restrição de terra (velha fronteira agrícola). Segundo o autor, os lotes sem restrição de terra $(a, b)$ chegaram mais facilmente aos sistemas de produção diversificados em cultivos anuais, cultivos perenes e pecuária (tipo 4). No caso dos lotes com (a) restrição de trabalho e abundância de terra, a diversificação produtiva se estabelece de forma gradual, por meio de baixa disponibilidade de capital e de esforços de trabalho fisiológico da própria família, enquanto na situação seguinte, em lotes com (b) abundância de trabalho e terra, a diversificação produtiva é apoiada pela entrada de capital de crédito rural, evolução demográfica da família e, eventualmente, contratação de trabalho temporário e investimento em mecanização agrícola. 
Costa (2000) também demonstra que o grupo com (a) restrição de trabalho e abundância de terra (nova fronteira agrícola) empreendeu esforços alternados entre introdução de pastagens e culturas perenes, isto é, nas suas trajetórias, há períodos em que se faz esforço de implantação de pastagens com redução no incremento das áreas com culturas perenes, e períodos em que, inversamente, as taxas de crescimento das pastagens caem e as de formação de plantios com culturas perenes sobem. Nesse sentido, a pecuária, além do advento do crédito rural a partir da institucionalização do Fundo Constitucional de Financiamento do Norte (FNO) nos anos 90, cumpre papel na capitalização para posterior introdução de sistemas perenes. Já o grupo com (b) abundância de trabalho e terra conduziu, durante sua trajetória, processos concomitantes de implantação de culturas perenes e pastagens.

Os dados de Mattos (2010) demonstram semelhanças aos registrados por McCracken et al. (2002), Perz (2001) e Costa (2000) quanto à relação positiva entre "tamanho do lote" e "introdução da atividade pecuária". Os tipos 4 (cultivos anuais + cultivos perenes + pecuária) e 5 (pecuária extensiva sem manejo de pastagens) são mais presentes em lotes com tamanho entre 50-100 hectares, enquanto o tipo 2 (cultivos anuais + pecuária) se destaca mais em lotes com tamanho superior a 100 hectares.

No estudo de Mattos (2010), a "titulação da terra" não demonstrou efeito significativo para tipologias de uso da terra. Em torno de 69,1\% das famílias selecionadas pelo Proambiente não detêm o título da terra, mas esta particularidade, apesar de não implicar em diferença significativa no uso da terra, demonstra-se relevante nos processos de capitalização por valorização dos lotes titulados superior aos não titulados.

A rentabilidade econômica condiciona-se ao "acesso ao crédito rural" para fomentar, "transporte para escoar" e "energia elétrica para beneficiar" a produção. Quando o mercado consumidor é pequeno e a elasticidade de preço demanda é nula, a rentabilidade da inovação agroecológica pode diminuir ou desaparecer com o tempo, ao revés, quando o mercado consumidor é grande, com demanda altamente elástica, obviamente tem-se uma situação mais favorável para efetivação dos investimentos sustentáveis, inclusive aos agricultores familiares menos capitalizados. Assim, novas trajetórias produtivas sustentáveis necessitam ser apoiadas pela presença renovada do Estado brasileiro (Martine, 1989), com oferta de infra-estrutura, crédito rural, políticas de preços mínimos, compra de alimentos e seguro agrícola. O uso diversificado da terra também é determinante quanto às possibilidade de inserção no mercado consumidor.

Mattos (2010) demonstra que 70,73\% dos lotes do Proambiente com "renda familiar anual" superior a US\$ 10 mil detêm sistemas agroecológicos baseados no tipo 4 (cultivos anuais + cultivos perenes + pecuária), percentual que decresce conforme a queda de renda familiar anual $(62,40 \%$ entre 
US \$ 5-10 mil; 58,63\% entre US\$ 3-5 mil; $52,37 \%$ entre US $\$ 1-3$ mil; $51,59 \%$ entre US\$ 0,5-1 mil; 46,43\% entre US\$0,25-0,5 mil). Em torno de 30\% dos lotes com nível intermediário de renda familiar anual transitam no tipo 2 (cultivos anuais + pecuária) $30,36 \%$ entre US\$ 0,25-0,5 mil; 29,94\% entre US $\$ 0,5-1,0$ mil; $33,62 \%$ entre US $\$ 1-3$ mil), percentual que decresce em intervalos de renda familiar anual mais elevados (24,82\% entre US\$3-5 mil; $23,55 \%$ entre US\$ 5-10 mil). No patamar mais elevado (acima de US\$ 10 mil) e entre os intervalos inferiores de renda familiar anual (abaixo de US\$ 0,25 mil) não há casos estatisticamente significativos no tipo 2 (culturas anuais + pecuária).

Mattos (2010) também deixa evidente a importância do "acesso ao crédito rural" para alavancar sistemas mais rentáveis e sustentáveis. Expressivos $16,09 \%$ dos lotes com tipo 1 (cultivos anuais) ainda aparecem entre os sem acesso ao crédito rural, sendo que lotes com demais tipos de uso da terra não figuram nessa categoria de forma estatisticamente representativa, o que denota que o acesso ao crédito rural é relevante para superar o estágio de produção de subsistência ou de depressão econômica. Os acessos aos créditos rurais do FNO e Programa Nacional de Fortalecimento da Agricultura Familiar (PRONAF) significam alavanca econômica para o tipo 4 (cultivos anuais + cultivos perenes + pecuária), onde figuram em torno de $62,00 \%$ dos lotes $(61,91 \%$ com FNO; 61,57\% com PRONAF), e ain- da $54,44 \%$ dos lotes com "outros tipos de crédito rural", restando $36,32 \%$ dos lotes sem acesso ao crédito rural. Portanto, os dados demonstram que o crédito rural alavanca a diversificação produtiva sustentável e a geração de renda familiar anual, embora um pouco mais da metade deles, que não possuem acesso ao crédito rural, também tenham estabelecido estratégias semelhantes. Estes dados corroboram os achados de Costa (2000) de que esforços próprios das famílias rurais, em situações de escassez de trabalho e capital, também resultam em sistemas diversificados e lucrativos, embora de forma mais lenta.

Mas existem diferenças qualitativas importantes entre o FNO, uma linha de crédito rural regional, e o PRONAF, uma linha de crédito rural nacional, que se evidenciam nas análises do tipo 2 (cultivos anuais + pecuária) e tipo 3 (cultivos anuais + cultivos perenes). Enquanto 27,18\% dos lotes com acesso ao crédito rural do PRONAF figuram no tipo 2 (cultivos anuais + pecuária), esse percentual se limita a apenas $11,11 \%$ dos lotes com acesso ao crédito rural do FNO. Vale a ressalva que lotes com outros tipos de crédito rural detêm expressiva marca de 34,45\%, enquanto os sem acesso ao crédito rural giram em torno de $21,89 \%$ com o tipo 2 (cultivos anuais + pecuária). Ou seja, os lotes sem acesso ao crédito rural alavancam o tipo 2 (cultivos anuais + pecuária), ainda que de forma mais lenta, a partir da própria reprodução da atividade pecuária, sendo que o acesso ao crédito rural do PRONAF 
e, principalmente, a outros tipos de crédito rural induzem processos de pecuarização mais rápidos, ao passo que mutuários do crédito rural do FNO inserem-se em outros sistemas produtivos. Isso fica claro na análise do tipo 3 (cultivos anuais + cultivos perenes), onde figuram $20,40 \%$ dos lotes sem acesso ao crédito rural e 17,13\% dos lotes com acesso ao crédito rural do FNO, valor que cai a 3,97\% entre os lotes com acesso ao crédito rural do PRONAF e a zero entre aqueles lotes com acesso a outros tipos de crédito rural. De novo os dados corroboram os achados de Costa (2000), onde a introdução de sistemas perenes pode ser feita com ou sem o acesso ao crédito rural, mas de forma mais intensa com a alavanca de capital externo, desde que qualificado na forma do FNO. No tipo 5 (pecuária extensiva - sem manejo de pastagens), há 5,31\% dos lotes sem acesso ao crédito rural ou 4,96\% com acesso ao crédito rural do PRONAF, o que mais uma vez apresenta o perfil mais voltado para produtos do PRONAF, enquanto o FNO detém uma estratégia mais condizente para estimular sistemas mais diversificados, economicamente viáveis e ambientalmente sustentáveis (Mattos, 2010).

Segundo Mattos (2010), lotes sem "acesso ao transporte" ainda transitam com expressiva importância no tipo 1 (culturas anuais) (14,63\% sem versus $2,65 \%$ com acesso ao transporte) e tipo 3 (culturas anuais + culturas perenes) $(27,91 \%$ sem versus $8,76 \%$ com acesso ao transporte), enquanto o acesso aumenta a participação de lotes com tipo 2 (culturas perenes + pecuária) $(13,28 \%$ sem versus $19,14 \%$ com acesso ao transporte) e, principalmente, tipo 4 (culturas anuais + culturas perenes + pecuária) $(40,38 \%$ sem versus $64,97 \%$ com acesso ao transporte), sendo pouco relevante a mudança no tipo 5 (pecuária extensiva - sem manejo de pastagens) (3,79\% sem versus $4,48 \%$ com acesso ao transporte). Os dados demonstram também que o acesso ao transporte aumenta o contingente pecuário dos lotes, portanto, é uma alternativa viável para capitalização dos lotes sem acesso rodoviário para escoamento da produção.

A análise de Mattos (2010) ainda evidencia os efeitos do "acesso à energia elétrica" na produção familiar. Os lotes sem acesso à energia elétrica, em comparação aos com acesso, transitam com maior importância no tipo 1 (culturas anuais) (7,64\% sem versus $5,74 \%$ com acesso à energia elétrica), tipo 3 (culturas anuais + culturas perenes) (21,02\% sem versus zero com acesso à energia elétrica) e tipo 5 (pecuária extensiva - sem manejo de pastagens) (4,67\% sem para zero com acesso à energia elétrica), enquanto o acesso aumenta a participação de lotes com tipo 2 (culturas perenes + pecuária) $(14,01 \%$ sem versus $24,88 \%$ com acesso à energia elétrica) e tipo 4 (culturas anuais + culturas perenes + pecuária) (52,65\% sem versus $65,55 \%$ com acesso à energia elétrica). $\mathrm{O}$ acesso à energia elétrica aumenta os contingentes pecuários mais tecnificados (tipos $2 \mathrm{e}$ 4) em comparação aos menos intensivos em capital (tipo 5), assim como o 
não acesso direciona para o cultivo de subsistência (tipo 1) ou para os cultivos de perenes menos tecnificados (tipo 3) em relação aos sistemas agroecológicos mais tecnificados (tipo 4).

De forma geral, o acesso ao transporte para escoamento e à energia elétrica para beneficiamento da produção eleva a produtividade marginal do trabalho e alavanca a rentabilidade econômica dos estabelecimentos familiares, mas não com a mesma sustentabilidade que confere o acesso ao crédito rural do FNO. Logo, os resultados põem em xeque modelos de desenvolvimento quanto à superação da dicotomia entre produção econômica e meio ambiente e trazem à tona a discussão sobre valoração de serviços ambientais integrados à produção agrícola.

\section{CONCLUSÕES}

A efetivação de políticas públicas de apoio à agricultura de pequena escala e de desenvolvimento rural no Brasil, nos últimos anos, torna-se ainda mais relevante com a publicação dos resultados do Censo Agropecuário 2006. No entanto, o uso do termo geral "agricultura familiar" para definir o público analisado pelo IBGE encobre grande diversidade de arranjos sociais, aspectos culturais e sistemas econômicos pertencente ao universo de produtores de pequena escala. Sendo assim, é fundamental que políticas públicas apoiem-se nas diferenças internas da categoria e nas diferentes formas com se relacionam com o uso da terra e dos recursos naturais para que essa hete- rogeneidade não seja simplificada ou congelada no tempo, mas valorizada como patrimônio sociocultural e potencial produtivo da agricultura brasileira. A separação das categorias de produção de pequena e grande escala também não deve servir para diferenciá-las entre passado e modernidade. Está mais do que claro nos dados do Censo Agropecuário 2006 que a agricultura de pequena escala tende a se fortalecer ao longo do tempo, o que resulta na demanda por políticas de incentivo produtivo e por investimentos em infra-estrutura rural, dentro de um recorte que resulte num processo de desenvolvimento econômico ecológico e de superação de processos de itinerância interna e externa de certos setores da produção de pequena escala. Nada indica que os produtores de pequena escala são resistentes à intensificação produtiva, mas que as opções que lhes são dispostas contêm incompatibilidades com seus processos gradativos de transição agroecológica.

A política pública do Proambiente surge como proposta dos movimentos sociais rurais da Amazônia que promove a participação e inclusão social, o desenvolvimento territorial, o planejamento econômico ecológico dos lotes rurais com uma leitura sobre as demandas gradativas de transição agroecológica e a prestação de serviços ambientais em escala de paisagem rural.

Os resultados do presente artigo quanto aos 2.400 lotes selecionados pelo Proambiente demonstram que, de maneira geral, os processos de transição 
agroecológica da agricultura de pequena escala da Amazônia são catalisados por investimentos em infra-estrutura básica em zonas rurais e pela oferta de crédito rural. Ainda que a transição agroecológica possa prescindir do acesso ao crédito rural e à infra-estrutura de transporte para escoamento e energia elétrica para beneficiamento da produção, ela se dá de forma substancialmente mais lenta ao longo do tempo, o que induz processos de capitalização mais paulatinos. Enquanto sem acesso a fontes externas de capital, em geral, a diversificação de sistemas produtivos necessita ser realizada de forma alternada entre pecuária e cultivos perenes (com a primeira atividade alavancando capital para a segunda), o acesso a essas fontes externas permite desencadear processos concomitantes. Vale a ressalva que tempo de ocupação do lote, escolaridade, composição familiar e tamanho do lote também se manifestam como variáveis importantes na transição agroecológica e nos processos de capitalização familiar.

\section{AGRADECIMENTOS}

Este estudo é parte da tese de Doutorado do primeiro autor, que agradece à Empresa Brasileira de Pesquisa Agropecuária (EMBRAPA) pelo suporte financeiro ao projeto.

\section{REFERÊNCIAS}

Abramovay, R. 1999. Agricultura familiar e desenvolvimento territorial. Reforma Agrária - Revista da Associação Brasileira de Reforma Agrária (ABRA) 28 (1, 2, 3) e 29
(1): 1-21.

Abramovay, R. 1998. Paradigmas do capitalismo agrário em questão. São Paulo/Campinas: HUCITEC / Editora da Unicamp.

Brookfield, H.C. 2001. Exploring agrodiversity. New York: Columbia University Press.

Brondízio, E. S., A. Cak, M. Caldas, C. Mena, R. Bilsborrow, C. Futemma, T. Ludewigs, E. Moran, \& M. Batistella. 2009. Small farmers and deforestation in Amazonia, in Amazonia and Global Change: $A$ Synthesis of $L B A$ Research. Editado por M. Keller, J. Gash \& P. S. Dias. Cidade: editora.

Brondízio, E. S., S. D. Mc Cracken, E.F. Moran, A. D. Siqueira, D. R. Nelson, D. R., \& C. Rodriguez-Pedraza. 2002. The colonist footprint: Toward a conceptual framework of land use and deforestation trajectories among small farmers in the Amazonian frontier, in Deforestation and land use in the Amazon, pp. 133-161. Editado por C. H. Wood \& R. Porro. Gainsville, FL: University Press of Florida.

Brondízio, E.S. \& A. D. Siqueira. 1997. From extractivists to forest farmers: changing concepts of caboclo agroforestry in the Amazon estuary. Research in Economic Anthropology 18: 223-279.

Brumer, A. 2001. Qual a “vocação” produtiva da agricultura familiar? Globalização, produção familiar e trabalho na agricultura gaúcha, in Agricultura familiar: realidades e perspectivas. Organizado por J. C. Tedesco, J.C. $3^{\mathrm{a}}$ ed. Passo Fundo: EDIUPF.

Cancian, F. 1989. Economic behavior in peasant communities, in Economic Anthropology, pp. 127-170. Editado por S. Plattner. California: Stanford University Press.

Carvalho, V. R. V. 2000. Inovação, diversificação cultural e sociabilidade, in Agricultura familiar em transformação no nordeste 
Paraense: o caso de Capitão Poço. Organizado por F. de A. Costa. Belém: NAEA/UFPA.

Chayanov, A. 1923. Die Lehre von der bauerlichen Wirtschaft. Versuch einer Theorie der Familienwirtschaft im Landbau. Berlim: Verlag Paul Parey.

1974. La organización de la unidad económica campesina. Buenos Aires: Nueva Visión.

Costa, F. de A. 2000. Economia camponesa e dinâmica inovativa: o caso eloquente de Capitão Poço, in Agricultura Familiar em Transformação no Nordeste Paraense: o caso de Capitão Poço. Organizado por F. de A. Costa. Belém: NAEA/UFPA.

Guanziroli, C., A. Romeiro, A. M. Buainain, A. Di Sabatto, \& G. Bittencourt. 2001. Agricultura familiar e reforma agrária no século XXI. Rio de Janeiro: Garamond.

Hetch, S. 1993. The logic of livestock and deforestation in Amazonia. Bioscience 43(10): 687-695.

IBGE 2009. Censo Agropecuário 2006 - agricultura familiar. Rio de Janeiro: IBGE.

Kautsky, K. 1980. A Questão Agrária. São Paulo: Proposta Editorial.

Lamarche, H. (coord.) 1994. L'agriculture familiale. Du mythe à la réalité. Paris, L'Harmattan.

Lênin, V.I.U. 1969. O desenvolvimento do capitalismo na Rússia. São Paulo: Abril Cultural.

Martine, G. 1989. Fases e fases da modernização agrícola brasileira. São Paulo: Iban (inédito).

Mattos, L. 2010. Decisões sobre uso da terra e dos recursos naturais na agricultura familiar amazônica: o caso do PROAMBIENTE. Tese de Doutorado. Campinas: Instituto de Economia, Universidade Estadual de Campinas (Unicamp).
Mattos, L. (Org.) 2010. Marco Referencial de Agroecologia. Brasília: EMBRAPA.

McCracken, S. D., A. Siqueira, A., E. F. Moran, E. S. Brondízio. 2002. Land use patterns on an agricultural frontier in Brazil. Insights and examples from a demographic perspective, in Deforestation and land use in the Amazon, pp: 162-192. Editado por C. H. Wood \& R. Porro. Gainsville, FL: University Press of Florida.

McCracken, S. D., E. S. Brondizio, D. Nelson, E. F. Moran, A. D. Siqueira \& C. Rodriguez-Pedraza. 1999. Remote sensing and GIS at farm property level: Demography and deforestation in the Brazilian Amazon. Photogrammetric Engineering \& Remote Sensing, 65(11): 1311-1320.

Moran, E.F. 2009. Interações homem-ambiente em ecossistemas florestais: uma introdução, in Ecossistemas florestais: interação homem-ambiente. Organizado por E. F. Moran \& E. Ostrom. Traduzido por D. S. Alves \& M. Batistella. São Paulo: Editora Senac/Edusp.

Netting, R. McC. 1989. Smallholders, householders, freeholders: why the family farm works well worldwide, in The household economy: reconsidering the domestic mode of production. Editado por R. R. Wilk. San Francisco/London: Westview Press.

Pan, W. K. Y., S. J. Walsh, R. E. Bilsborrow, B. G. Frizzelle, C. M. Erlien, \& F. Baquero. 2004. Farm-level models of spatial patterns of land use and land cover dynamics in the Ecuadorian Amazon. Agriculture Ecosystems \& Environment 101(2-3): 117 134.

Perz, S. G. \& Walker, R. 2002. Household life cycles and secondary forest cover among small farm colonists in the Amazon. World Development 30(6): 1009-1027.

Perz, S. G. 2001. Household demographic factors as life cycle determinants of land 
use in the Amazon. Population Research and Policy Review 20(3): 159-186.

Pichon, F. J. 1996. Settler agriculture and the dynamics of resource allocation in frontier environments. Human Ecology: 24(3): 341-371.

Romeiro, A. R. 1998. Agricultura Familiar em Áreas de Reforma Agrária. Síntese Regional. Região Norte. Brasília: FAO/INCRA.

Roseberry, W. 1993. Beyond the agrarian question in Latin America, in Confronting Historical Paradigms: peasant, labor, and the Capitalism World System in Africa and Latin America. Editado por F. Cooper, F. E. Mallon, S. J. Stern, A. F. Isaacman, \& W. Roseberry. Madison: University of Wisconsin Press.

Schneider, S. (Org.) 2006. A Diversidade da Agricultura Familiar. Porto Alegre: Editora da UFRGS.

Schultz, T. W. 1965. A transformação da agricultura tradicional. Rio de Janeiro: Zahar.

Van der Ploeg, J. D. 2006. O modo de produção camponês revisitado, in $A D i$ versidade da Agricultura Familiar. Organizado por S. Schneider. Porto Alegre: Editora da UFRGS.

Van Wey, L.K., E. Ostrom \& V. Meretsky. 2009. Teorias subjacentes ao estudo de interações homem-ambiente, in Ecossistemas florestais: interação homem-ambiente. Organizado por E. F. Moran \& E Ostrom. Tradução de D. S. Alves \& M. Batistella. São Paulo: Senac/ Edusp.

Van Wey, L.K., A. D'Antona \& E. S. Brondízio. 2007. Household demographic change and land use / land cover change in the Brazilian Amazon. Population and Environment 28: 163-185.

Wanderley, M. N. B. 2001. Raízes históricas do campesinato brasileiro, in Agricultura familiar: realidades e perspectivas. Organizado por J. C. Tedesco. $3^{\text {a }}$ ed. Passo Fundo:
EDI/UPF. . 2003. Agricultura familiar e campesinato: rupturas e continuidade. Estudos Sociedade e Agricultura: Estudos Sociedade e Agricultura 21: 42-61.

Recebido em 30/04/2010.

Aprovado em 03/09/2010. 